\title{
Educational and Training Models in Forensic Psychology
}

\author{
David DeMatteo \\ Drexel University
}

\author{
Daniel A. Krauss \\ Claremont McKenna College
}

\author{
Geoffrey Marczyk \\ Newton Square, Pennsylvania
}

Jeffrey Burl

Drexel University

\begin{abstract}
The field of forensic psychology has experienced remarkable growth over the past three decades. Perhaps the best evidence of this growth is the number of forensic psychology training programs currently enrolling students. Those interested in forensic psychology can choose from several types of programs aimed at different educational outcomes. In addition, opportunities for postdoctoral fellowships, continuing education, and respecialization have become increasingly more available. Despite the increased availability of forensic psychology training programs, there is little consensus regarding the core substantive components of these programs. This article will summarize the existing educational and training models in forensic psychology programs and then identify a core set of competencies that should be considered for inclusion in doctoral-level forensic psychology training curricula to adequately prepare students for the increasingly varied roles assumed by forensic psychologists.
\end{abstract}

Keywords: forensic psychology, law-psychology, training models, model curricula

The field of forensic psychology has quite recently emerged as a distinct subdiscipline within professional psychology. Despite a historical lineage dating back to the early 1900s and the influential publication of Hugo Munsterberg's (1908) On the Witness Stand, the American Psychological Association (APA) did not formally recognize forensic psychology as a discrete specialization until 2001 (Otto \& Heilbrun, 2002). Although specialty recognition by APA in any area of psychology other than clinical, counseling,

DAVID DeMATTEO received his PhD in Clinical Psychology from MCP Hahnemann University and JD from Villanova Law School. He is an Assistant Professor of Psychology at Drexel University, and Co-Director of the JD/PhD Program in Law and Psychology. His research interests include forensic psychology, psychopathy, and drug policy.

GeOFFrey MARCZYK received his PhD in Clinical Psychology from MCP Hahnemann University and JD from Villanova Law School. He is currently in private practice in Newtown Square, PA. His research interests include forensic psychology, organizational behavior, and leadership development.

DANIEl A. KRAuss received a joint $\mathrm{PhD}$ in psychology (clinical psychology and psychology, policy, and law) and JD from the University of Arizona. He is an Associate Professor of Psychology at Claremont McKenna College. His research explores the intersection of psychology and the legal system.

JeFFREY BuRL received his MA in Forensic Psychology from John Jay College of Criminal Justice (CUNY) in 2007. He is currently a student in the $\mathrm{PhD}$ Program in Clinical Psychology at Drexel University. His research interests include forensic assessment and treatment.

We thank Kirk HeIlbrun and Don Bersoff for their helpful advice regarding the content of this article. We would also like to thank Kathleen Kemp for her helpful research assistance.

CORRESPONDENCE CONCERNING THIS ARTICLE should be addressed to David DeMatteo, JD, PhD, Drexel University, Department of Psychology, MS 626, 245 N. 15th Street, Philadelphia, PA 19102. E-mail: dsd25@drexel.edu school, or industrial-organizational is a relatively recent development, the recent recognition of forensic psychology as a specialty area was arguably overdue in light of the field's long history and rapid growth over the past 30 years.

One indicator of the growth of forensic psychology is the number and range of educational and training opportunities available to students and practitioners. The development of the first joint-degree law-psychology graduate training program in 1973 at the University of Nebraska marked the beginning of a paradigm shift in how forensic practitioners are educated and trained (Bersoff, 1999). A number of law-psychology and forensic psychology programs have been developed since that time, and students and practitioners interested in forensic psychology now have a range of educational and training options from which to choose.

Despite the increased availability of forensic psychology training programs, there is little consensus regarding the core educational components of these programs. Given the rapid growth of the field of forensic psychology, it is critical that training programs provide students with the necessary breadth of knowledge, skills, and experiences. Ensuring proper training takes on additional importance because of the increasingly varied roles being assumed by forensic psychologists in the areas of assessment, treatment, and consultation (Marczyk, DeMatteo, Kutinsky, \& Heilbrun, 2008).

This article will first review the divergent and expanding roles assumed by forensic psychologists. We will then examine the educational and training models currently used in forensic psychology programs and consider whether these training models are adequately preparing students for forensic practice. Finally, we will offer a substantive training curriculum that emphasizes the core competencies that arguably should be included in doctorallevel forensic psychology training programs. It is important to note that a model curriculum for doctoral-level forensic psychology 
graduate programs has not yet been developed, and we hope that our proposed model will stimulate further discourse on this important topic. Although this article may primarily benefit training directors from doctoral-level programs that offer forensic psychology training, we believe this article will also prove useful for those who are less familiar with specialized training opportunities in forensic psychology. As student interest in forensic psychology continues to increase, it is becoming increasingly more important for nonforensic professionals to be able to educate their students about available training opportunities.

\section{Defining the Role of the Modern Forensic Psychologist}

Psychologists have a long tradition of providing services to the legal system (see Bartol \& Bartol, 2006, and Otto \& Heilbrun, 2002, for comprehensive summaries). Initial interaction between psychologists and the legal system, beginning in the early 1900s, consisted of the provision of clinical services to incarcerated adult offenders and juvenile offenders in detention centers (Otto \& Heilbrun, 2002). Other early activities of psychologists providing services to criminal justice and the legal system included psychological fitness testing of law enforcement personnel and the pretrial evaluation of criminal offenders (Bartol \& Bartol, 2006). These early efforts helped to cement the relationship between psychologists and the legal system, and the use of psychologists for evaluating law enforcement personnel, criminal offenders, and civil litigants has now become commonplace (Melton, Petrila, Poythress, \& Slobogin, 2007). The U.S. Court of Appeals for the District of Columbia Circuit decision in Jenkins v. United States (1962), which held that appropriately qualified psychologists could testify in court as experts in psychiatric disorders and that psychological measures could be introduced in court to support their expert opinions, further expanded psychological practitioners, interactions within the courts. Following this decision, the use of psychologists as expert witnesses in judicial proceedings has increased dramatically, with thousands of forensic evaluations conducted each year on a variety of psycholegal issues (Otto \& Heilbrun, 2002).

Although forensic psychologists now assume a prominent role within the forensic mental health and criminal justice systems, there is a vigorous debate within the parent field of law and psychology regarding the definition of forensic psychology and roles that may be appropriately assumed by forensic psychologists (Brigham, 1999; Hess, 2006). It is generally understood that forensic psychology is one specialty area within the broader rubric of law and psychology research and practice (Hess, 2006), but there is less agreement regarding the precise definition and scope of forensic psychology. At its basic level, forensic psychology can be conceptualized as the application of the science and profession of psychology to questions and issues relating to the law and the legal system. This is the definition of forensic psychology adopted by the American Board of Forensic Psychology (ABFP, 2006). Although most practitioners would likely agree, at least in principle, with the core components of this definition, there is considerable disagreement over the scope of forensic psychology and what activities (i.e., research, assessment, and treatment) and roles should appropriately be considered the exclusive province of forensic psychology.
On the one hand, forensic psychology could be narrowly defined as only encompassing clinical psychology, counseling psychology, school psychology, or another specialty recognized by the APA, and consisting only of activities that provide clinical psychological expertise to the judicial system. This was the definition of forensic psychology endorsed by the American Psychology-Law Society, which is Division 41 of the APA, when it initially pursued formal specialty recognition for forensic psychology from the APA (Heilbrun, 2000; see Forensic Specialty Council, 2007). This definition only encompasses clinically based areas of psychology and therefore excludes practitioners without clinical degrees. Under this narrow and restrictive definition, research psychologists in the fields of social, experimental, and cognitive psychology would not be considered forensic psychologists, despite the obvious contribution that these researchers can make in certain legal contexts (e.g., reliability of eyewitness testimony, perceptions of jurors). It is important to note that this narrow definition may have been chosen for both practical and legal reasons. Practically, specialty recognition from APA is generally reserved for clinically based subspecialties, while legally many states prohibit the term "psychologist" from being used by psychological professionals who are not licensed by the state. It is rare that nonclinical practitioners would seek state licensure in such a jurisdiction and, as a result, research psychologists who study law-psychology issues could not legally refer to themselves as forensic "psychologists," nor would they likely meet the requirements for specialty certification imposed by APA.

Dissatisfaction with narrow conceptualizations of forensic psychology soon emerged, which led to the proposal of several broader definitions. For example, the Committee on the Revision of the Specialty Guidelines for Forensic Psychology (2006) recently adopted a broader definition of forensic psychology, which was subsequently endorsed by the American Psychology-Law Society. Under this definition, forensic psychology includes "all professional practice by any psychologist working within any subdiscipline of psychology ... when the intended purpose of the service is to apply the scientific, technical, or specialized knowledge of psychology to the law and to use that knowledge to assist in solving legal, contractual, and administrative problems" (1.03). This more expansive definition of forensic psychology reflects the widely varying roles that can be assumed by forensic professionals in terms of both clinical practice and research. This definition encompasses the clinically based activities of forensic psychologists, including policy psychology (i.e., application of clinical skills to law enforcement and public safety), correctional psychology (i.e., provision of assessment and treatment services in correctional settings), and forensic mental health assessment (i.e., assessment of criminal offenders and civil litigants to assist courts in answering legal questions) (Bartol \& Bartol, 2006), while also recognizing that nonclinical/research psychologists are engaging in forensic psychology research if their research interfaces with some aspect of the legal system.

Several prominent researchers and commentators have also offered broader definitions of forensic psychology that include both clinical and nonclinical aspects. For example, Grisso (1987) defined a forensic psychologist as "any psychologist, experimental or clinical, who specializes in producing or communicating psychological research or assessment information intended for application to legal issues" (p. 831). Bartol and Bartol (2006) offered a 
similarly broad definition when they defined forensic psychology as "both (1) the research endeavor that examines aspects of human behavior directly related to the legal process ... and (2) the professional practice of psychology within or in consultation with a legal system that embraces both civil and criminal law and the numerous areas where they intersect" (pp. 3-4). Finally, Goldstein (2007) recently defined forensic psychology as "the application of psychological research, theory, practice, and traditional and specialized methodology . . . to provide information relevant to a legal question" (p. 5).

\section{Educational and Training Opportunities in Forensic Psychology}

Regardless of the precise definition, it is clear that the field of forensic psychology has experienced remarkable conceptual and empirical advances in the past three decades (Grisso, 2003; Heilbrun, 2001; Melton et al., 1997). These advances have been fueled by increased attention to the law's demands (Melton et al., 2007); the development of specialized forensic assessment instruments (e.g., Grisso, 1998; Grisso \& Appelbaum, 1998; Monahan et al., 2005; Quinsey, Harris, Rice, \& Cormier, 2006); the founding of interdisciplinary professional organizations and journals (Otto \& Heilbrun, 2002); and substantial growth in research, scholarship, and practice-related literature (e.g., Goldstein, 2007; Heilbrun, 2001; Heilbrun, Marczyk, \& DeMatteo, 2002). As a result of this growth, psychologists are being called upon with increasing frequency to conduct forensic mental health assessments, provide treatment, and serve as consultants in a variety of criminal and civil contexts. Changes in the health care reimbursement system for psychologists have also caused forensic practice to become particularly appealing to more general clinical practitioners because forensic services are often not financially constrained by managed care (Melton et al., 2007). Because of this increase in interest, it is important that forensic psychology training programs adequately prepare students to engage in high-quality forensic practice, and more general clinical training programs should also be advised to supplement their basic training with forensically oriented courses and training opportunities to more fully meet the needs of their students. The growth and development of forensic psychology is perhaps best evidenced by looking at the number and diversity of educational and training opportunities available to students and practitioners (Krauss \& Sales, 2006; Marczyk et al., 2008). These opportunities range from undergraduate survey courses examining the broad intersection of law and psychology to joint-degree graduate programs offering terminal degrees in both law (JD) and psychology (PhD or PsyD). Moreover, opportunities for continuing education and postdoctoral specialization in forensic psychology are becoming increasingly more available.

As the popularity of forensic psychology has increased in recent years, the availability of forensic psychology training programs has increased almost commensurately. Forensic psychology training programs, or more general programs that offer a forensic psychology track or concentration, have proliferated rapidly in the past two decades. As will be discussed, a variety of educational and training opportunities in forensic psychology now exist at the undergraduate, graduate, and postdoctoral levels, and they offer a wide variety of educational and training opportunities in both clinical and nonclinical (i.e., research-based) forensic psychology.
Even beyond the doctoral degrees, there are opportunities for advanced credentialing (i.e., board certification) for forensic practitioners who wish to distinguish themselves as having specific expertise in forensic psychology.

Despite the remarkable growth in educational and training opportunities in forensic psychology, there is little consensus regarding appropriate training models, curricula, and training goals (see Bersoff et al., 1997, and Krauss \& Sales, 2006, for discussions of this problem). The field of forensic psychology continues to broaden in scope and diversity, and it encompasses a wide range of knowledge and skills (e.g., knowledge of legal standards; research skills; assessment, intervention, and consultation skills). As such, training programs must consider the varied roles that may be assumed by forensic psychologists. Although forensic psychology training programs have increased in number, scope, and sophistication in recent years, important questions remain regarding the structure, focus, and goals of these programs.

The following sections will examine the educational and training opportunities available to students and practitioners interested in forensic psychology. After discussing the various training models employed in these programs, we will discuss a proposed model curriculum for doctoral-level programs that would serve to adequately prepare students to become forensic practitioners. Rather than ending the debate regarding appropriate training models, we hope that our proposed curriculum will stimulate further discussion of this important topic.

\section{Undergraduate Training in Forensic Psychology}

Many colleges and universities currently offer at least one undergraduate course that covers some aspect of law-psychology, including forensic psychology. Several surveys conducted in the 1990s revealed an increase in the number of undergraduate lawpsychology courses being offered (Ogloff, Tomkins, \& Bersoff, 1996), with many high-ranked psychology departments offering at least one law-psychology course (see Bersoff et al., 1997, for a review of this research). Anecdotally, law-psychology courses, particularly courses on forensic psychology, are among the most popular course offerings at the undergraduate level.

Recent years have witnessed an increase in the number and diversity of undergraduate law-psychology courses. Whereas most undergraduate courses offered in years past were survey courses that focused broadly on the intersection between law and psychology, newer courses offer a more detailed and sophisticated examination of circumscribed aspects of law and psychology. For example, undergraduate courses are being offered on child witnesses, the role of psychology in the legal process, and social science applications to the law (see the American Psychology-Law Society Web site [www.ap-ls.org] for a listing of available courses). A more recent development is the offering of undergraduate degrees in forensic psychology. John Jay College of Criminal Justice now offers a Bachelor of Arts in Forensic Psychology that provides training in psychological theory, research methods, and the application of psychological principles to specific areas in the legal system. Of note, employment opportunities are somewhat restricted for those with bachelor-level training in forensic psychology. Although some graduates may find employment in various agencies or institutions, such as police departments, social service 
agencies, or court systems, these programs typically function to prepare students for additional education/training.

\section{Graduate Training in Forensic Psychology}

Despite recent advances in course offerings and curricula in forensic psychology at the undergraduate level, educational and training opportunities for undergraduates interested in forensic psychology are still quite limited. There are considerably more educational and training opportunities in forensic psychology for students in graduate training programs. Depending on one's academic and professional interests, various options are available at both the master's and doctoral levels, and there are also several clinical and nonclinical joint-degree programs available for those who wish to obtain formal training in both law and psychology (see Krauss \& Sales, 2006).

According to the Guide to Graduate Programs in Forensic and Legal Psychology (2007-2008) [hereinafter referred to as the "Guide to Graduate Programs"], which was created by the Teaching, Training, and Careers Committee of the American Psychology-Law Society, there are nearly 50 programs that offer graduate training in forensic psychology (see also Burl, Shah, \& DeMatteo, 2008). Broadly speaking, these programs can be categorized by program focus (e.g., clinical forensic psychology, nonclinical legal psychology), training models (e.g., clinical scientistpractitioner, nonclinical scientist-scholar), and degrees awarded (e.g., masters, doctorate, joint-degree) (Krauss \& Sales, 2006). On a more practical level, graduate programs in law and psychology, and forensic psychology more specifically, differ quite considerably in terms of length of training. These programs can range from 2 to 7 years postbachelor's degree, with many students taking closer to 10 years to complete joint-degree programs. As the following discussion illustrates, those interested in forensic psychology have a rich variety of graduate training programs from which to choose.

There are roughly 12 programs that offer a master's degree in forensic psychology. Identifying the exact number of programs is difficult, because some programs do not admit students on a regular basis and other programs use terminology that makes it difficult to determine the exact nature of the training. Some of these programs are clinical in nature, while others are nonclinical. In terms of program goals, some programs are designed to prepare students for research or clinical positions within various institutions and professional agencies, such as prisons, juvenile facilities, social service agencies, police departments, probation and parole departments, court systems, and community mental health centers. Other programs seek to prepare students for continued training in $\mathrm{PhD}$ programs, with the recognition that graduates of doctoral programs typically have more employment opportunities (see Morgan, Kuther, \& Habben, 2004).

There are a variety of educational and training opportunities available in forensic psychology in doctoral programs. A review of published program descriptions and the Guide to Graduate Programs reveals that there are approximately 10 programs in which students can obtain a $\mathrm{PhD}$ in clinical psychology with a formal concentration (focus or specialty track) in forensic psychology, and there are roughly the same number of PsyD programs that have a formal programmatic emphasis in forensic psychology. In addition, another approximately 10 programs offer a $\mathrm{PhD}$ in other areas of psychology, such as social or experimental, with a formal concentration in forensic psychology, legal psychology, or psychology and law. Several of these programs offer a $\mathrm{PhD}$ specifically in forensic psychology or legal psychology. Using a less formal approach, students in programs in which forensic psychology is not a core component can obtain relevant training and experience by working with faculty with forensic interests who offer relevant courses and practical experience.

Finally, there are several joint-degree programs $(\mathrm{JD} / \mathrm{PhD}$ or JD/PsyD) for those students interested in obtaining formal training in both law and psychology. As of this writing, six programs offered JD/PhD (or JD/PsyD) programs in law and psychology: Drexel University, Pacific Graduate School of Psychology in cooperation with Golden Gate Law School, Simon Fraser University in cooperation with the University of British Columbia, University of Arizona, University of Nebraska, and Widener University (JD/ PsyD). In some of these programs, students can pursue clinical or nonclinical psychology training. Of particular note is the University of Nebraska, which offers several joint-degree options, including JD/PhD, JD/MA, and PhD/MLS (i.e., Master's of Legal Studies, which is a nonpractitioner degree requiring the student to complete the equivalent of 1 year of law school education). There are also several schools that permit students to pursue a JD and $\mathrm{PhD}$ concurrently, but that offer no formal or coordinated/ integrated curricula in law and psychology.

Students pursuing a $\mathrm{PhD}$ or PsyD in clinical psychology (or other applied areas of psychology, such as counseling and school psychology) must complete a 1-year APA-accredited predoctoral internship prior to receiving their degree. A substantial number of internships offer training and clinical/research experience in forensic psychology. A review of the internship programs listed in the Association of Psychology Postdoctoral and Internship Centers (APPIC) directory indicates that $209(47.1 \%)$ of the 444 APAaccredited internship programs in the U.S. report offering a minor rotation in forensic/correctional psychology, and 74 (16.7\%) of the 444 programs report offering a major rotation. As these numbers demonstrate, it has become commonplace for clinical internships to offer at least some experience in forensic settings. These internships differ greatly in terms of the range and depth of forensic experiences that are offered. A student interested in general clinical practice might benefit from completing a minor forensic rotation. This clinical experience would, at the very least, offer the beginnings of the knowledge and training necessary to pursue (if desired) later forensic practice and training. Other internships provide students with a forensic rotation with more expansive but still limited forensic activities (e.g., conducting assessments of criminal offenders), while still other internships, such as those offered by the Federal Bureau of Prisons, are entirely forensically focused and provide students with a range of clinical experiences that are specifically directed at forensic assessment, treatment, and consultation among correctional populations. These specialized internships are ideal for those seeking to build upon an existing base of forensic knowledge, experience, and skills. Completing a forensic-focused internship is an effective way to broaden and refine one's repertoire of forensic knowledge and skills, and it can serve as a stepping-stone for obtaining employment in a specific area of forensic psychology. A forensic-focused internship is also useful for those students 
without significant forensic experience who are seeking to specialize in forensic psychology.

\section{Postdoctoral Training and Continuing Education in Forensic Psychology}

There are several forensic psychology training opportunities available at the postdoctoral level, including formal postdoctoral fellowships and Continuing Education programs. Indeed, much of the specialty training in forensic psychology occurs after completion of the doctorate degree (Otto \& Heilbrun, 2002). A postdoctoral fellowship in forensic psychology provides intensive, supervised research and/or practical experience. These types of fellowships are ideal for those with previous forensic experience seeking to specialize in a particular area of forensic psychology, or for individuals trained in nonclinical programs seeking to obtain respecialization training in clinical psychology with a forensic emphasis. For those with forensic experience, a forensic postdoctoral fellowship will provide highly intensive, specialized forensic experience (typically 1 or 2 years), and it may serve as a useful way of obtaining employment working with specific forensic populations. Furthermore, postdoctoral fellowships are useful for those seeking licensure as a psychologist because states typically require licensure candidates to obtain a set amount of postdoctoral supervised experience after receiving their doctorate. These fellowships will also meet one component of the training requirements for achieving board certification in forensic psychology (this issue is discussed more fully in the section entitled "Credentialing in Forensic Psychology"). Individuals trained in nonclinical areas of psychology seeking to pursue a career in forensic psychology can use a postdoctoral fellowship to respecialize in clinical psychology with a forensic emphasis. The respecialization process typically requires additional educational and experiential requirements, and it can take several years to complete.

Practitioners can also enhance their forensic knowledge and skills by attending Continuing Education (CE) seminars. CE programs are available on a wide variety of topics within forensic psychology, and they are appropriate for practitioners with varying levels of forensic skills and experience. While some CE programs are one-time 3-hr sessions that provide an introduction to a broad topic area within forensic psychology, other CE programs consist of intensive 3-day workshops that provide highly specific training on a particular assessment instrument or intervention approach. It is important to note that a growing number of states require (either by statute or regulation) that professionals obtain certification through additional training, examination, or both before they can begin conducting forensic evaluations. According to a survey conducted by Farkas, DeLeon, and Newman (1997), nine states required training for certification and 14 states offered or planned to offer formalized training (see Otto \& Heilbrun, 2002). Without a doubt, many more states today are likely to require standardized training for professionals to provide a wide array of forensic services.

\section{Credentialing in Forensic Psychology}

After obtaining a doctorate and working in the field for several years, individuals seeking to distinguish themselves as having advanced expertise in forensic psychology can seek board certifi- cation. Although several boards offer certifications, the most highly respected is the American Board of Professional Psychology (ABPP), which has been incorporated since 1947. Board certification by ABPP is the only postdoctoral specialty certification recognized by the APA Directory (ABFP, 2006). The ABPP offers certification in 13 specialty areas of psychology, including clinical psychology, neuropsychology, and forensic psychology. The credential identifying the highest level of competence in forensic psychology is the Diplomate in Forensic Psychology awarded by the ABFP, which operates as an affiliated member of ABPP. The ABFP awarded the first Diploma in Forensic Psychology in 1978. Eligibility criteria to apply for Diplomate status include the following: a doctoral degree in professional psychology from a program accredited by the APA or Canadian Psychological Association (or listed in the Doctoral Psychology Programs Meeting Designation Criteria); licensure or certification at the independent practice level as a psychologist in the State, Province, or Territory in which the psychologist practices; a minimum of 100 hours of formal education, direct supervision, or continuing education in forensic psychology; and a minimum of 1,000 hours of experience in forensic psychology obtained by either the completion of a full-time (at least 1-year) postdoctoral training program in forensic psychology (approved by the American Board of Forensic Psychology) or practice over a minimum period of 4 postdoctoral years. The examination process involves a written and oral examination, with the latter being based on the submission of two practice samples.

\section{Basic Competencies and Training Models in Forensic Psychology}

Although forensic psychology training programs have increased in both number and popularity in recent years, there is little consensus regarding which training models are most appropriate. It is important to note that the debate over appropriate training models in forensic psychology is not new (Bersoff, 1999; Bersoff et al., 1997; Freeman \& Roesch, 1992; Otto, Heilbrun, \& Grisso, 1990; Poythress, 1979). It is also likely that the continuing increase in forensic psychology programs and the increases in interest for forensic training will force the field to reexamine current training models and, perhaps, develop new ones as the field continues to expand. Moreover, as the roles of forensic psychologists continue to expand into new areas of research and practice, it is important that training programs properly prepare future researchers and practitioners by incorporating educational, training, and practical experiences that provide a solid foundation of forensic-related knowledge and skills.

The lack of consensus regarding appropriate training models for forensic psychology may in part reflect the lack of consensus regarding the definition of forensic psychology and the roles that forensic psychologists may properly assume. As previously discussed, some definitions of forensic psychology focus almost exclusively on the clinical aspects of the profession, while other definitions are broader and consider areas of law-psychology research that are not exclusively clinical in nature. For example, although few would dispute that forensic mental health assessments of criminal offenders (e.g., competence to stand trial, mental state at the time of the offense) fall within the scope of forensic psychology, there is less agreement regarding whether psycholegal 
research conducted by cognitive, social, and experimental psychologists should be considered forensic psychology (e.g., reliability of expert testimony, perceptions of jurors). For the purposes of this article, we will use a broad definition of forensic psychology that encompasses both research and practice.

There are several training goals that may be appropriate in doctoral-level forensic psychology programs (Krauss \& Sales, 2006). On the broadest level, students can be trained to become clinicians (i.e., applied forensic psychology), researchers (clinical or nonclinical), or both. Using this broad categorization, we will summarize the three training models predominantly used in doctoral-level psychology and forensic psychology programs.

Some programs train students to become scientist-practitioners using the Boulder model. Students in these programs are trained in the science and practice of clinical and forensic psychology, and graduates are particularly well suited for careers in research, academia, and practice. Because a key goal of scientist-practitioner training is scientifically based clinical practice, this model is only employed in clinical and counseling programs. Other clinically based programs follow a practitioner-scientist model of training. These programs focus less on research and more on the clinical/ applied aspects of psychology (e.g., PsyD programs). Students in these programs typically receive a heavy dose of practice-focused coursework and experiential training. Finally, some forensic psychology programs prepare students to become scientist-scholars, with either a clinical or nonclinical focus. Many of these programs are in areas other than clinical psychology, such as cognitive, developmental, and social psychology, and they train students to engage in empirical research designed to increase our forensic knowledge base and inform public policy. These three categories of training models are admittedly broad and not necessarily mutually exclusive or exhaustive, but they provide some indication of the types of training available in forensic psychology programs.

Given the expanding roles of forensic psychologists, it is admittedly challenging to design a graduate program that provides all of the educational, training, and experiential components needed to properly prepare students for a forensic career. This is particularly true given the time-limited nature of graduate training and differences between clinical and nonclinical forensic psychologists. Nevertheless, we believe it is possible to identify a core set of basic competencies that should be emphasized in doctoral-level forensic psychology training programs. We recognize that the APA Committee on Accreditation (2008) provides programs with considerable leeway when developing training models, provided that the training models cover the core areas identified by the Committee on Accreditation and have curricula designed to achieve their stated goals and objectives. As such, we are not arguing that all programs should blindly adopt our proposed curricula. With that said, we believe our proposed curricula is a solid starting point in terms of identifying core competencies in forensic training programs, and we hope it is useful in stimulating continued discussion on this issue.

Although most specialty training in forensic psychology takes place at the postdoctoral level (Otto \& Heilbrun, 2002), we chose to focus on doctoral-level training programs because our proposed curriculum is designed to offer foundational skills that will prepare graduates to (1) engage in practice without additional training (after obtaining licensure, if needed), or (2) seek more advanced training and experience at the postdoctoral level. At a minimum, it would seem that forensic practitioners should obtain training and experience in the following areas:

(1) Substantive psychology, including core knowledge of basic areas of psychology central to one's major area of study (e.g., clinical, developmental, experimental, cognitive);

(2) Research design/methodology and statistics, designed to prepare students to conduct research and/or be informed consumers of research;

(3) Conducting research, consisting of performing original empirical research that culminates in a doctoral dissertation (except in PsyD programs);

(4) Legal knowledge, including foundations of the legal system, sources of law, legal research, relevant civil and criminal case law, criminal and civil procedures relevant to forensic practice, legal rules and professional guidelines relating to expert testimony, and substantive law in relevant areas (e.g., competence to stand trial, mental state at the time of the offense);

(5) Integrative law-psychology knowledge, including introductory/overview foundational courses on forensic psychology, and knowledge of research in psycholegal areas such as eyewitness testimony, jury decision-making, admissibility of scientific testimony, forensic assessment measures and techniques, and the treatment of offender populations;

(6) Ethics and professional issues, relating to general research and practice (e.g., Ethical Principles of Psychologists and Code of Conduct (APA, 2002), and forensic research and practice (e.g., Specialty Guidelines for Forensic Psychologists (Committee on the Revision of the Specialty Guidelines for Forensic Psychology, 2006); and

(7) Clinical forensic training (for those in clinical training programs), including forensic mental health assessments, forensically based interventions, and/or forensic consultation.

We believe that a focus on these core areas would adequately prepare doctoral-level students for basic forensic practice. These training elements were identified through several means, including a review of the Guidelines and Principles for Accreditation of Programs in Professional Psychology (2008) promulgated by the APA's Committee on Accreditation, which informed the broad and general training components of the curriculum, a review of existing forensic psychology training curricula, and a review of relevant literature and guidelines on forensic training. The forensic components overlap to some extent with the training goals identified by the Forensic Specialty Council (2007) in its educational and training guidelines, although the elements in the above proposal are narrower in scope and designed to train graduate students as opposed to residents. 
Of note, the first three elements would likely fall under the "broad and general" rubric identified by the APA's Committee on Accreditation (2008), meaning that they are foundational skills not specific to forensic psychology. According to the Committee on Accreditation (2008), broad and general training provides students with knowledge in scientific psychology and the foundations of practice, which prepares them for entry-level practice in professional psychology. As such, forensic psychology training programs would typically need to focus on adding the remaining four elements to their curricula. If these topic areas are covered through a combination of course work (required and elective), research experience, and practical experience, the inclusion of these elements should not lengthen the overall course of study for doctoral students.

We reviewed the curricula for the roughly 35 doctoral or jointdegree programs that offer training in forensic psychology to get an idea of how many programs incorporate the forensic components of the proposed curricula (i.e., not elements 1, 2, and 3, which fall under the "broad and general" rubric). Unfortunately, outdated posted curricula, ambiguous course titles and descriptions, and unclear training foci complicated this task, so the results should be treated with caution. Our review reveals that roughly $40 \%$ of the programs report offering one or more courses that would fall under the "Legal Knowledge" component, which includes courses on legal procedures, civil or criminal law, and mental health law. All of the programs report offering courses that would fall under the "Integrated Law-Psychology Knowledge" component, which includes introductory/overview foundational courses on forensic psychology and courses on forensic assessment and intervention. Of note, however, most of these programs offer introductory courses, with roughly $60 \%$ offering a forensic assessment course and $30 \%$ offering a forensic intervention course. Although all programs report offering a general ethics course, only three programs report offering a course on "Ethics and Professional Issues" specifically related to forensic psychology. The descriptions of the practical training were often unclear, but it appears that nearly all clinical $\mathrm{PhD}$ and $\mathrm{PsyD}$ programs offer practical experience in forensic psychology, which would satisfy the "Clinical Forensic Training" component.

Overall, these findings suggest that most programs offer coursework that would satisfy the forensic components of the proposed curricula. However, less than half of the programs report offering legal knowledge coursework, and a large number of programs satisfy the integrated law-psychology component by offering an introductory course. Finally, only three programs have curricula that would satisfy all four forensic components of the proposed curricula (mostly due to the small number of programs that report offering ethics courses in forensic psychology).

It is important to note that only those forensic psychology training programs that are housed within clinical, counseling, or school psychology programs are eligible for APA accreditation. Stand-alone forensic programs are not currently accredited by the APA, and it remains an open empirical question whether such accreditation would serve to increase the quality of training that students receive and resulting forensic practice. A recent development, however, is the accreditation of postdoctoral fellowships in forensic psychology. A set of educational and training guidelines prepared by the Forensic Specialty Council (which includes representatives from the American Psychology-Law Society, Ameri- can Board of Forensic Psychology, and American Academy of Forensic Psychology) in 2007 were recently endorsed by the Council of Specialties in Professional Psychology. As such, postdoctoral fellowships in forensic psychology can apply for APA accreditation.

\section{Conclusion}

Given the increasing involvement of forensic psychologists in the civil and criminal justice systems, and the increasing numbers of students who are studying forensic psychology, it is critical that existing training programs adequately prepare future practitioners to assume a variety of roles. Just as traditional $\mathrm{PhD}$ programs in clinical psychology (at least those that adhere to the Boulder model) prepare students to function in a variety of roles (e.g., researcher, clinician, academic), it is essential that forensic psychology training programs prepare students to assume several different roles. Rather than creating specialists, forensic psychology training programs would be better advised to provide students with a foundational level of competence in a variety of core component areas, which is consistent with the guidelines promulgated by the APA's Committee on Accreditation (2008) in terms of preparing students for entry-level practice in professional psychology. Specialization in a particular area of forensic psychology would seem to be best achieved at the postdoctoral level after the student has obtained a core set of competencies.

\section{References}

American Board of Forensic Psychology. (2006). ABFP brochure. Retrieved May 8, 2008, from http://www.abfp.com/brochure.asp

American Psychological Association. (2002). Ethical principles of psychologists and code of conduct. American Psychologist, 57, 1060-1073.

American Psychological Association Committee on Accreditation. (2008). Guidelines and principles for accreditation of programs in professional psychology. Washington, DC: Author.

American Psychology-Law Society. (2008). Guide to graduate programs in forensic and legal psychology (2007-2008). Southport, NC: Author.

Bartol, C., \& Bartol, A. (2006). History of forensic psychology. In I. B. Weiner \& A. K. Hess (Eds.), The handbook of forensic psychology (3rd ed., pp. 3-27). Hoboken, NJ: Wiley.

Bersoff, D. N. (1999). Preparing for two cultures: Education and training in law and psychology. In R. Roesch, S. D. Hart, \& J. R. P. Ogloff (Eds.), Psychology and law: The state of the discipline (pp. 375-401). New York: Kluwer Academic/Plenum Press Publishers.

Bersoff, D. N., Goodman-Delahunty, J., Grisso, J. T., Hans, V. P., Poythress, N. G., \& Roesch, R. G. (1997). Training in law and psychology: Models from the Villanova conference. American Psychologist, 52, 1301-1310

Brigham, J. (1999). What is forensic psychology anyway? Law \& Human Behavior, 23, 273-298.

Burl, J., Shah, S. B., \& DeMatteo, D. (2008, August). Graduate training in forensic psychology: A survey of training models. Poster session presented at the 116th Annual Convention of the American Psychological Association (APA), Boston.

Committee on the Revision of the Specialty Guidelines for Forensic Psychology. (2006). Specialty guidelines for forensic psychologists (second official draft). Retrieved December 13, 2006, from http://www .ap-ls.org/links/SGFP\%20January\%202006.pdf

Farkas, G. M., DeLeon, P. H., \& Newman, R. (1997). Sanity examiner certification: An evolving national agenda. Professional Psychology: Research and Practice, 28, 73-76. 
Forensic Specialty Council. (2007). Education and training guidelines for forensic psychology. Retrived August 8, 2008, from http://umassmed.edu/uploadedFiles/ET\%20Guidelines\%20final.pdf

Freeman, R. J., \& Roesch, R. (1992). Psycholegal education: Training for forum and function. In D. K. Kagehiro \& W. S. Laufer (Eds.), Handbook of psychology and law (pp. 567-576). New York: Springer-Verlag.

Goldstein, A. M. (2007). Forensic psychology: Toward a standard of care. In A. M. Goldstein (Ed.), Forensic psychology: Emerging topics and expanding roles (pp. 3-41). Hoboken, NJ: Wiley.

Grisso, T. (1987). The economic and scientific future of forensic psychological assessment. American Psychologist, 9, 831-839.

Grisso, T. (1998). Instruments for assessing understanding and appreciation of Miranda rights. Sarasota, FL: Professional Resource Press.

Grisso, T. (2003). Advances in assessments for legal competencies. In T. Grisso (Ed.), Evaluating competencies: Forensic assessments and instruments (2nd ed., pp. 1-20). New York: Kluwer.

Grisso, T., \& Appelbaum, P. S. (1998). MacArthur Competence Assessment Tool for Treatment (MacCAT-T). Sarasota, FL: Professional Resource Press.

Heilbrun, K. (2000). Petition for the recognition for a specialty in professional psychology. Submitted on behalf of the American Board of Forensic Psychology and the American Psychology-Law Society to the American Psychological Association.

Heilbrun, K. (2001). Principles of forensic mental health assessment. New York: Kluwer Academic/Plenum Press

Heilbrun, K., Marczyk, G. R., \& DeMatteo, D. (2002). Forensic mental health assessment: A casebook. New York: Oxford University Press.

Hess, A. K. (2006). Defining forensic psychology. In I. B. Weiner \& A. K. Hess (Eds.), The handbook of forensic psychology (3rd ed., pp. 28-58). Hoboken, NJ: Wiley.

Jenkins v. United States, 307 F. 2 d 637 (D. C. Cir. 1962).

Krauss, D. A., \& Sales, B. D. (2006). Training in forensic psychology: Training for what goal? In I. B. Weiner \& A. K. Hess (Eds.), The handbook of forensic psychology (3rd ed., pp. 851-871). New York: Wiley.
Marczyk, G., DeMatteo, D., Kutinsky, J., \& Heilbrun, K. (2008). Training in forensic assessment and intervention: Implications for principlesbased models. In R. Jackson (Ed.), Learning forensic assessment (pp. 3-31). New York: Routledge (Taylor \& Francis Group).

Melton, G., Petrila, J., Poythress, N., \& Slobogin, C. (2007). Psychological evaluations for the courts: A handbook for mental health professionals and lawyers (3rd ed.). New York: Guilford Press.

Monahan, J., Steadman, H., Appelbaum, P., Grisso, T., Mulvey, E., Roth, L., et al. (2005). Classification of violence risk (COVR). Lutz, FL: Psychological Assessment Resources.

Morgan, R. D., Kuther, T. L., \& Habben, C. J. (Eds.) (2004). Life after graduate school in psychology: Insider's advice from new psychologists. New York: Psychology Press.

Munsterberg, H. (1908). On the witness stand: Essays on psychology and crime. New York: Doubleday.

Ogloff, J. R. P., Tomkins, A. J., \& Bersoff, D. N. (1996). Education and training in law/criminal justice: Historical foundations, present structures, and future developments. Criminal Justice \& Behavior, 23, 200 235.

Otto, R. K., \& Heilbrun, K. (2002). The practice of forensic psychology: A look toward the future in light of the past. American Psychologist, 57, $5-18$.

Otto, R. K., Heilbrun, K., \& Grisso, T. (1990). Training and credentialing in forensic psychology. Behavioral Sciences \& the Law, 8, 217-231.

Poythress, N. G. (1979). A proposal for training in forensic psychology. American Psychologist, 34, 612-621.

Quinsey, V. L., Harris, G. T., Rice, M. E., \& Cormier, C. A. (2006). Violent offenders: Appraising and managing risk (2nd ed.). Washington, DC: American Psychological Association.

Received May 13, 2008

Revision received October 20, 2008

Accepted October 27, 2008 